\title{
NHENHENHÉM DE GRICE SOBRE A IRONIA
}

\author{
Jair Antônio de Oliveira \\ Professor de Comunicação Social da \\ UFPR
}

\begin{abstract}
Resumo:
As implicaturas conservacionais propostas por H. P. GRICE cons tituem um exemplo paradigmático do poder de explicação pragmática dos fenômenos lingüísticos, especificamente quando se trata de significar "algo mais" do que é realmente dito. No entanto, tal perspectiva não é suficiente para interpretar enunciados irônicos - pois estes são produ zidosa partir da suposição de que há conhecimento compartilhado entre locutor e ouvinte - o que nem sempre acontece.
\end{abstract}

"There is no merit whatever in upsetting a canonical interpretation merely for the sake of destroying something that may have been built with considerable care". (Paul de Man)

Introdução

LEVISON (1) considera as implicaturas conservacionais propostas por GRICE (2) como uma das idéias mais geniais dentro do escopo da Pragmática e as coloca como exemplo paradigmático do poder de explicação pragmática dos fenômenos lingüísticos.

Atribui às implicaturas o poder de explicar o que é significado a mais do que é realmente dito, isto é:

\section{"mais do que é literalmente expresso pelo sentido convencional da expressão lingüística enunciada". (3)}

Grice merece os elogios pelo fato de suas idéias terem ampla aceitação nos meios acadêmicos e estarem presentes em grande número de trabalhos sobre a linguagem. De qualquer modo, isto não o isenta de críticas em relação a determinados aspectos de sua teoria, em especial, a questão do reconhecimento da intenção do locutor por parte do ouvinte quando o primeiro está sendo irônico.

Para o autor de Lógica e Conversação a ironia não representa um problema e é facilmente compreendida pelo interlocutor,

"(...) hence, Grice claims, ironies arise and are successfully decoded".(4) 
O conceito de ironia em Grice está associado à explícita violação pragmática de uma de suas máximas conversacionais, a Máxima de Qualidade (5) , onde os enunciados são transparentemente falsos, por exemplo:

\section{A: E se a URSS bloquear o Golfo e o petróleo? \\ B: Qual é! a Grã-Bretanha domina os mares!}

(Algum participante razoavelmente informado saberá que o enunciado de $B$ é flagrantemente falso. Sendo assim, B não pode estar tentando enganar $A$. $O$ único caminho em que a suposição de que $B$ é co-operativo é se nós considerarmos que $B$ está significando algo diferente do que é dito. Procurando ao redor por uma proposição relacionada e cooperativa que $B$ talvez tenha intencionado transmitir, nós chegamos ao oposto, ou negação, do que B afirmou, notadamente que a GrãBretanha não domina os mares, e deste modo, pela relevância do enunciado anterior, a sugestão de que não há nada que a Grã-Bretanha possa fazer). (6)

A violação da Máxima de Qualidade para a obtenção de um efeito irônico está associada à expressão de um sentimento, atitude ou avaliação. Não podemos dizer alguma coisa ironicamente a menos que o que pretendemos dizer reflita uma hostilidade, um julgamento depreciativo ou um sentimento como a indignação ou o desprezo.

Convém observar que Grice, ao associar a ironia com uma manifestação negativa em relação ao interlocutor, apenas retoma a concepção clássica do fenômeno. É uma posição semelhante à assumida pelos antigos retóricos que viam na ironia uma espécie de tropo e, como tal, deve ter o seu sentido figurado substituído por um sentido literal. A diferença é que, no caso de Grice, o significado figurado é reanalisado como uma implicação figurada ou implicatura.

A proposta de substituição de um significado por outro é obscura, pois o ouvinte teria que procurar ao redor por uma proposição que fosse estritamente relacionada com a que foi expressa e interpretá-la como uma implicatura. A dificuldade reside em 'decidir' o que pode ser interpretado como proposição estritamente relacionada, especialmente uma que se fizesse representar por um enunciado figurado, pois, de uma maneira geral, a nossa percepção de parentesco entre as proposições não se dá apenas entre relações lógicas, mas também através de fatores psicológicos, sociais, culturais. Assim, em um enunciado irônico, o ouvinte deve considerar uma gama de proposições; algumas sendo expressas pelo enunciado e outras implicadas por ele.

Em acréscimo ao que a proposição expressa ou implica, um enunciado pode sugerir ao ouvinte certas linhas não proposicionais de interpretação. Por exemplo, pela evocação de imagens ou estados mentais, que são precisamente as características dos enunciados figurados, e não podem ser totalmente analisados dentro da estrutura de Grice. (7) 
Máxima de Qualidade, há situações em que o locutor - pretendendo ser irônico expressa literalmente a verdade. Ou situações onde, simultaneamente, pretende transmitir o que é dito realmente e o que está implicado conversacionalmente. Como neste exemplo: "uma pessoa diz: 'Eu tive um péssimo dia hoje' (na ocasião em que perdeu uma fortuna no jogo)". (8)

Mesmo distribuindo a análise da ironia através de todas as máximas (9) , pouco se pode fazer além do que ilustrar como a explícita violação de uma delas pode ou não resultar em ironia. Isto é, a sua compreensão fica restrita aos enunciados emitidos em conformidade com as propriedades específicas de cada máxima. Mas, nem todas as ironias podem ser recuperadas por este critério.

A rigor, uma dúvida pode ser captada em Grice quando fala sobre a existência de um tom prosódico específico para os enunciados irônicos:

Eu também estou em dúvidas se o tom irônico existe como tom específico. Suspeito que um tom irônico é sempre um tom depreciativo, desrespeitoso ou um tom conectado com um ou mais sentimentos ou atitudes. O que qualifica tais tons como irônicos é que eles aparecem, nesta e em outras ocasiões, quando uma observação irônica é feita. (10)

Mas tal dúvida não será ampliada para fora do âmbito prosódico. Impera a certeza griceana de que os usuários são cooperativos e com isso fica garantida a 'estabilidade' na relação linguagem-usuários.

\section{Conclusão}

O que Grice procurou fazer foi traçar uma distinção entre o que é realmente dito e o que está tacitamente implicado, sugerindo que cada aspecto da interpretação pode ser assinalado a uma ou a outra categoria. No caso da ironia, será sempre uma implicatura que substituirá o que foi dito pelo locutor.

É evidente que tal abordagem é insuficiente para a decodificação dos enunciados irônicos, mesmo que se considere o fenômeno em seu ponto mais fraco, aquele comumente registrado em dicionários: "Ironia. | Do grego eiróneia, 'interrogação', pelo lat. ironia |. S. f. 1. Modo de exprimir-se que consiste em dizer o contrário daquilo que se está pensando ou sentindo (...)".(11) Exceção seja feita às frases feitas, slogans, chavões, cuja forma e função têm sido rotinizada através do uso repetido em virtude de sua recorrência em livros didáticos e dicionários. Mas, nestes casos, a estratégia perde toda a sua força de impacto, sendo reduzida a mera observação de 'mau gosto', pois o que torna interessante o uso da ironia é a sutileza em colocar o inesperado para o interlocutor.

Como a pragmática griceana depende do reconhecimento do ouvinte da intenção lingüística do locutor, nos casos em que não há um conhecimento compartilhado comum entre ambos, a decodificação fica reduzida a uma questão de adivinhações. Pior: pode resultar em inferências não-autorizadas. Em determinadasregiões do Nordeste brasileiro, a palavra solteira, usada no contexto para indicar aquela que não é casada, tem conotação negativa de mulher da vida, prostituta. Alguém que 
desconheça este fato e tente ser irônico nessa região supondo que o interlocutor decodificará sem problemas a implicatura pode sofrer sérias perfurações por conta das "William James Lectures". (12)

Talvez não se chegue a um extremo como este, mas em situações onde o Princípio de Cooperação é violado de forma não intencional, digamos, por motivo de os interlocutores não compartilharem o mesmo universo lingüístico, o ouvinte fará inferências a partir do enunciado tomado literalmente na suposição de que o outro está sendo co-operativo.

Vamos imaginar o seguinte quadro:

( $A$ e $B$ conversam num contexto $X$ onde a palavra solteira é sinônimo de prostituta. $B$ desconhece isto.)

A diz para B: - Você precisa casar.

B responde e aponta para a irmã de A que passa no outro lado: - Que tal aquela solteirinha?...

O que deve ficar claro é que Grice e tantos outros que evocaram o Princípio de Cooperação têm refletido a postura lógica interessada na verdade e, desta forma, com o significado proposicional. Isto faz com que Grice deixe de considerar elementos indispensáveis em uma abordagem que é chamada Pragmática Conversacional, acreditando na relevância de sua Máxima de Qualidade.

Pode parecer irônico, mas Grice é o primeiro a violar a Máxima de Qualidade ao não fornecer um procedimento adequado para que os interlocutores decodifiquem a ironia. Ou sua discussão sobre o assunto está incompleta (as notas adicionais sobre o texto Lógica e Conversação necessitam de notas adicionais), ou é puro "nhenhenhém" (13) para não deixar lacuna na teoria. Qualquer que seja a opção, é bom nunca esquecer o quadro teórico em que Grice está circunscrito e, seguindo o velho chavão dos iluministas, Sapere Ande, desenvolver novas respostas. Pode ser um caminho a sugestão de Paul de MAN:
(...) tropes do not function by way of conventional associations between patterns of linguistics signs, on the one hand, and same recoverable meaning, on the other. There is no get of rules, no grammar of the trope, that will read the rhetorical aspect of a text the way a semantics reads the propositional aspects. (14)

\section{NOTAS DE REFERÊNCIA}

1. Levison, S.C. Pragmatics. Cambridge: Cambridge University Press, 1983. p. 97-118.

2.Ver H.P. Grice: Logic and Conversation (1975) e Meaning (1972).

3. LEVISON, p. 97. (tradução minha)

4. LEVISON, p. 108.

5. Não diga o que você acredita ser falso; não diga senão aquilo que de você possa fornecer evidência adequada.

6. LEVISON, p. 109. 
7. SPERBER, D. ; WILSON, D. On Grice's theory of conversation. In: WERTH, P. (Ed.). Conversation and discourse. London, 1981. p. 11.

8. KAUFER, David S. Understanding ironic communication. Journal of Pragmatics, NorthHolland, v. 5, p. 499. 1981.

9. Qualidade, relação, modo e quantidade.

10. GRICE, H.P. Further notes on logic and conversation. In: COLE, p. (Ed.). Pragmatics and semantics, 9. New York: Academic Press, 1978. P. 124.

11. FERREIRA, A. B. H. Novo dicionário da língua portuguesa. Rio de Janeiro: Nova Fronteira, 1975.

12. Leituras realizadas em Harvard (1967) onde Grice propôs parte de suas idéias chaves.

13. Conversa fiada. Falaciosa.

14. MAN, Paul de. In: APPIAH, A. Reviewing Norris, te descontructive turn: essay in the rhetoric of philosophy. Diacritics (Spring 1986). p. 49-64.

\section{REFERÊNCIAS BIBLIOGRÁFICAS}

FERREIRA, Aurélio Buarque de. Novo Dicionário da Língua Portuguesa. Rio de Janeiro: Nova Fronteira, 1978. GRICE, H. P. Further notes on logic and conversation. In: COLE, P. (ed.). Pragmatics and semantics, 9. New York: Academic Press, 1978. p. 113-27.

, Logic and conversation. In: COLE, P. \& MORGAN, J. (eds.). Syntax and semantics, 3: speech acts. New York: Academic Press, 1975.

KAUFER, David. Understanding ironic communication. Journal of Pragmatics, 5, 1981. p.495-510.

LEVISON, S. C. Pragmatics. Cambridge: Cambridge University Press, 1983.

SPERBER, Dan \& WILSON, Deirdre. On Grice's theory of conversation. In: WERTH, P. (ed.) Conversation and discourse. London: Croom Helm, 1981. p. 155-178. 